\title{
Oral administration of a curcumin-phospholipid delivery system for the treatment of central serous chorioretinopathy: a 12-month follow-up study
}

\author{
This article was published in the following Dove Press journal: \\ Clinical Ophthalmology \\ 21 May 2013 \\ Number of times this article has been viewed
}

\author{
Fabio Mazzolani' \\ Stefano Togni \\ 'Private Ophthalmology Practice, \\ 2Indena SpA, Milan, Italy
}

Correspondence: Fabio Mazzolani Private Practice, Via Pecchio 13, 20।3I Milan, Italy

Tel +39335802 44I7

Fax +39022940 8426

Email fabio.mazzolani@email.it
Background: The therapeutic effects of $\mathrm{Meriva}^{\circledR}$, a curcumin-phospholipid (lecithin) delivery system (formulated as Norflo ${ }^{\circledR}$ tablets), on visual acuity and retinal thickness in patients with acute and chronic central serous chorioretinopathy was previously investigated in a six-month open-label study.

Methods: In this follow-up study, visual acuity was again assessed by ophthalmologic evaluation and retinal thickness by optical coherence tomography (OCT). Norflo tablets were administered twice daily to patients with central serous chorioretinopathy. The study group consisted of 12 patients (total 18 eyes) who completed 12 months of follow-up. The primary endpoint was change in visual acuity before and after treatment with Norflo, and change in neuroretinal or retinal pigment epithelium detachment on OCT was the secondary endpoint.

Results: After 12 months of therapy, no eyes showed further reduction in visual acuity, $39 \%$ showed stabilization, and $61 \%$ showed statistically significant improvement $(P=0.0001$ by Student's $t$-test and $P=0.0005$ by Wilcoxon signed rank test). Ninety-five percent of eyes showed a reduction in neuroretinal or retinal pigment epithelium detachment and $5 \%$ showed stabilization. The difference in retinal thickness after 12 months was statistically significant ( $P=0.0001$ by Student's $t$-test and $P=0.0004$ by Wilcoxon signed rank test).

Conclusion: These results, albeit preliminary, confirm our previous finding that this curcumin delivery system is effective in the management of central serous chorioretinopathy. When administered in a bioavailable formulation, curcumin is worth considering as a therapeutic agent for the management of inflammatory and degenerative eye conditions involving activation of retinal microglial cells.

Keywords: curcumin, central serous chorioretinopathy, retinal pigment epithelium detachment, Norflo $^{\circledR}$, Meriva ${ }^{\circledR}$

\section{Introduction}

Serous neurosensory elevation of the retina is the hallmark of central serous retinopathy, also known as central serous chorioretinopathy (CSCR). ${ }^{1}$ CSCR causes visual impairment, often temporary and in one eye only, and mostly affects males aged 20-50 years. ${ }^{2}$ The condition was first described by Von Graefe in 1866, and named "recurrent central retinitis". ${ }^{3}$ In its acute form, CSCR is associated with focal leakage at the level of the retinal pigment epithelium and hyperpermeability of the choroid, as diagnosed by fluorescein angiography with indocyanine green angiography. ${ }^{4} \mathrm{CSCR}$ is characterized by blurred or distorted vision (metamorphopsia) with the finding of a blurred or gray spot in the central visual field being common when the retina 
is detached. The disorder is self-limiting in the majority of patients, but despite recovery of good vision overall, reduced visual acuity may persist after the fluid has disappeared. When CSCR does not resolve spontaneously, damage to the retinal pigment epithelium and photoreceptors can occur, with permanent visual impairment. ${ }^{2}$ The pathophysiology of CSCR remains fundamentally obscure, and several hypotheses have been put forward, including abnormal ion transport across the retinal pigment epithelium and focal choroidal vasculopathy. ${ }^{5,6}$ Notwithstanding the elusive nature of the pathophysiology of CSCR, it is now accepted that the cascade of events leading to neurosensory detachment includes, or might even be triggered by, changes in choroid permeability. ${ }^{7}$ Further, increasing attention is now focused on an inflammatory component in the onset and persistence of CSCR, because prostaglandins can cause vasodilation and increase the permeability of the blood-retinal barrier. This disruption may cause inflammation and further decompensation of the retinal pigment epithelium, resulting in a protracted disease course and extensive neurosensory detachment. Increased permeability manifests as weakening of the tight junctions between capillary endothelial cells and slowing of the active retinal fluid pumping mechanism in the pigment epithelium. ${ }^{8}$ Previous studies have identified ibuprofen and aspirin as promising agents for the treatment of this condition, ${ }^{9,10}$ in which elevated plasminogen activator inhibitor-1 concentrations are found. ${ }^{11,12}$

Curcumin, the yellow pigment of turmeric (Curcuma longa L.), is an important anti-inflammatory agent. With more than 100 drug targets identified so far ${ }^{13}$ and close to 5500 entries in PubMed (10\% of which directly correlated with inflammation), curcumin acts as a "master switch" for inflammation. ${ }^{14}$ The redundancy of targets makes it difficult to decipher the clinical translation of a biochemical signature of curcumin, but there is general agreement that the most important clinical targets of curcumin are transcription factors (NF-kB, nuclear factor kappa-light-chain-enhancer of activated B cells; STAT3, signal transducer and activator of transcription 3; Nrf2, NF-E2 related factor-2), and that curcumin can exert beneficial effects by modulating the genomic and cell signaling pathways involved in the inflammatory response. ${ }^{15,16}$ Within an anti-inflammatory context, curcumin-induced upregulation of peroxisome proliferator-activated receptor- $\gamma$ (PPAR- $\gamma$ ), a ligand-inducible transcription factor, plays a critical role, given that activation of PPAR- $\gamma$ controls the response of microglial cells and limits inflammation..$^{9,10,17-19}$ Curcumin is also being increasingly investigated in the treatment of eye conditions, showing potential value in the treatment of several ocular disorders, including cataract and uveitis, ${ }^{20-23}$ as well as diseases of the retina. ${ }^{24}$

The main problem that has prevented translation of curcumin from bench to bedside has been its very poor bioavailability. This issue has long plagued the clinical validation of its medicinal potential, but has now been substantially improved by various formulation strategies, with dispersion in a lecithin formulation (Meriva ${ }^{\circledR}$, Indena $\mathrm{SpA}$, Milan, Italy) being the best documented in terms of comparative pharmacokinetics and clinical efficacy. ${ }^{25-31}$ Overall, these observations provided a rationale for studying the effect of curcumin combined with phospholipids in patients with CSCR.

\section{Materials and methods}

Eighteen eyes from 12 patients ( 11 men and one woman) aged 29-68 years and with CSCR were enrolled in the study. These patients had participated in a previously reported pilot study lasting six months, with positive preliminary results. ${ }^{1}$ The patients included in this follow-up study were being followed in our tertiary referral retinal center in Milan, Italy. Diagnosis of CSCR was confirmed on optical coherence tomography (OCT, Spectralis, Heidelberg Engineering, Heidelberg, Germany) and angiography with fluorescein and green indocyanine. Ophthalmological examination included slitlamp examination, best-corrected visual acuity measurement using the Early Treatment Diabetic Retinopathy Study chart (Precision Vision, La Salle, IL, USA), intraocular pressure, and fundus examination with a Volk +90 D lens (VOLK Optical Inc., Mentor, OH, USA). Follow-up is ongoing, and all patients have successfully completed at least 12 months of treatment. All patients underwent complete ophthalmological examination at baseline and after six and 12 months. An ad hoc medical record reporting the findings for all patients at each follow-up visit was developed. A black and white Amsler grid was also recorded at each visit.

All patients received Meriva $1.2 \mathrm{~g} /$ day, representing a daily curcuminoid intake of $240 \mathrm{mg}$ (Meriva being composed of one part curcuminoids, two parts lecithin from nongenetically modified soy, and two parts of microcrystalline cellulose). Meriva was administered as a commercially available tablet formulation (Norflo ${ }^{\circledR}$, Eye Pharma, Genova, Italy). The patients took two tablets daily, each tablet containing $600 \mathrm{mg}$ of Meriva. The treatment was administered to patients who had experienced frequent relapses in the previous year and to treatment-naïve patients at the time of initial diagnosis. We also investigated satisfaction and tolerance of this additional complementary therapy using a questionnaire developed specifically to analyze tolerance and compliance with Norflo tablets. Visual acuity and 
neuroretinal or pigment epithelium detachment was assessed before and after treatment with Norflo. To prevent any possible complication due to the anatomical damage induced by the pathology, during the study period frequent controls were carried out in all patients (including monitoring visual acuity and OCT/angiography parameters). None of the patients needed to be switched from curcumin to other treatments.

\section{Statistical analysis}

The Student's $t$-test and the Wilcoxon signed rank test were used to test for statistically significant changes in bestcorrected visual acuity and retinal thickness. All statistical analyses were done using an Apple iMac computer with JMP 9.0.0 software (SAS Institute Inc, Cary, NC, USA). Notched box plots were constructed on the same computer using NCSS 2007 software.

\section{Results}

Mean best-corrected visual acuity improved from $0.63 \pm 0.2$ (Logarithm of the Minimum Angle of Resolution, logMAR $0.2 \pm 0.7)$ at baseline to $0.8 \pm 0.2(\log$ MAR $0.1 \pm 0.7)$ after 12 months of treatment. At the 12-month follow-up, no eyes showed reduction in visual acuity, 39\% were stable, and $61 \%$ were significantly improved $(P=0.0001$ by Student's $t$-test and $P=0.0005$ by Wilcoxon signed rank test, Figure 1). Average neuroretinal and/or retinal pigment epithelium detachment at baseline was $317.8 \pm 80.2 \mu \mathrm{m}$. After 12 months of therapy, $95 \%$ of eyes showed a reduction of neuroretinal or retinal pigment epithelium detachment and 5\% showed stabilization (Figures 2 and 3). After 12 months, mean neuroretinal and/or retinal pigment epithelium detachment decreased significantly to $268.1 \pm 54.9 \mu \mathrm{m}(P=0.0001$ by Student's $t$-test and $P=0.0004$ by Wilcoxon signed rank test). No statistically significant differences were observed for near best-corrected visual acuity, but all patients reported improvement in distortion, blurring, and discoloration on the Amsler grid. No systemic adverse effects were observed, with no dropouts during the study. The tolerability of the product was rated as very good by all patients.

\section{Discussion}

CSCR is an ocular disease for which the pathogenesis is still obscure. It is often described as idiopathic, acknowledging our current lack of understanding of its specific causative factors and mechanisms of occurrence. CSCR is frequently associated with various other conditions characterized by exposure to increased levels of endogenous or exogenous glucocorticoids, as shown by its association with Cushing's syndrome. CSCR is also prevalent in patients with type A behavior, and stressful events and pregnancy might represent other risk factors for the disease. All these conditions are characterized by hypercortisolism, and many cases of CSCR have been described during or following treatment with glucocorticoids for various systemic or ocular conditions. ${ }^{2,32}$ While a common feature in the onset and persistence of CSCR seems to be choroid permeability, ${ }^{7}$ increasing attention is being paid to the role of prostaglandins, which cause vasodilation
A

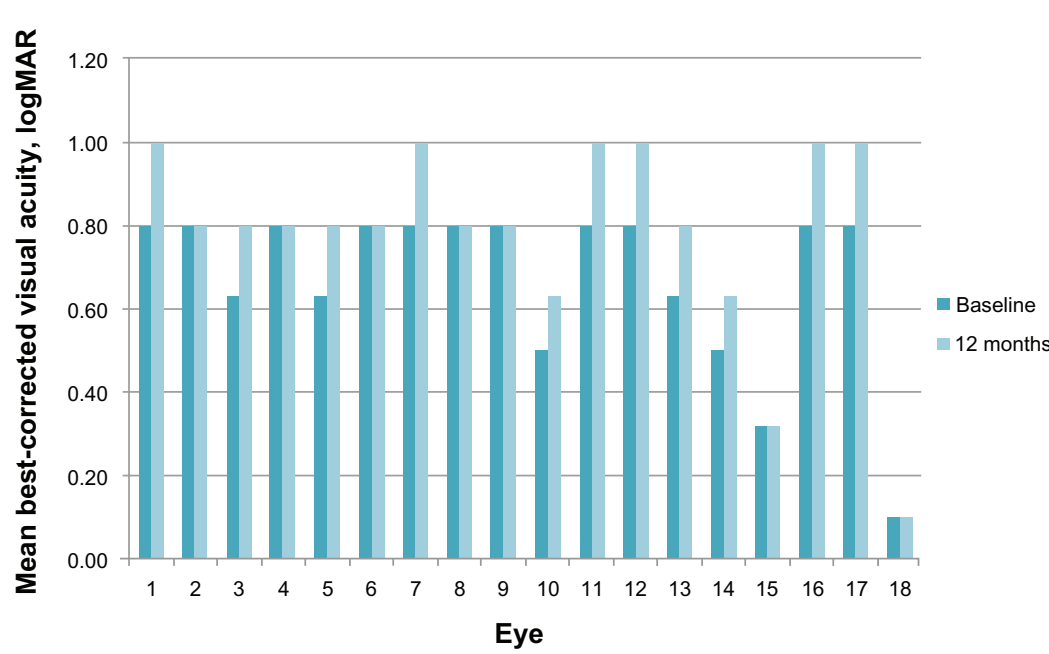

B

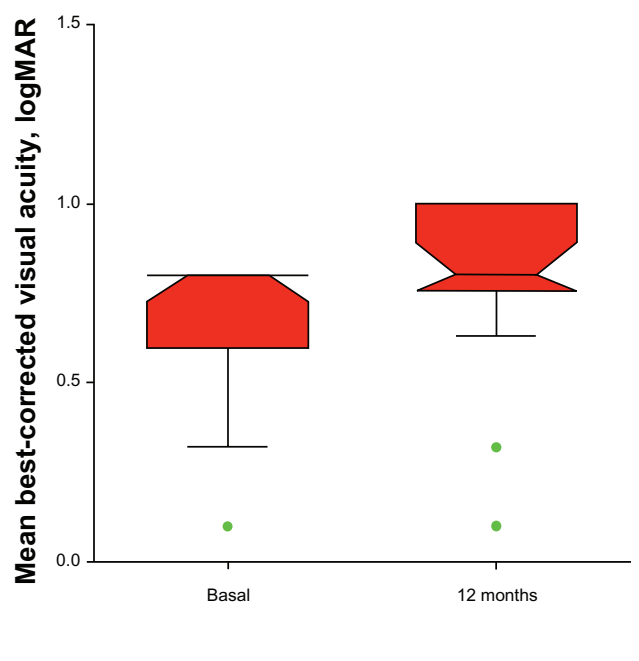

Figure I (A) Effect of the curcumin-lecithin formulation (Norflo ${ }^{\circledR}$ ) on visual acuity after six months of treatment. (B) The notched box plot shows the confidence interval around the median, which is normally based on the median $\pm 1.57 \times$ interquartile range/square root of $n$. According to this graphical method for data analysis, if the notches of the two boxes do not overlap, there is "strong evidence" ( $95 \%$ confidence) that their medians differ. Points outside the whisker boundaries are considered outliers (green $=$ mild).

Note: Norflo ${ }^{\circledast}$, Eye Pharma, Genova, Italy. 
A

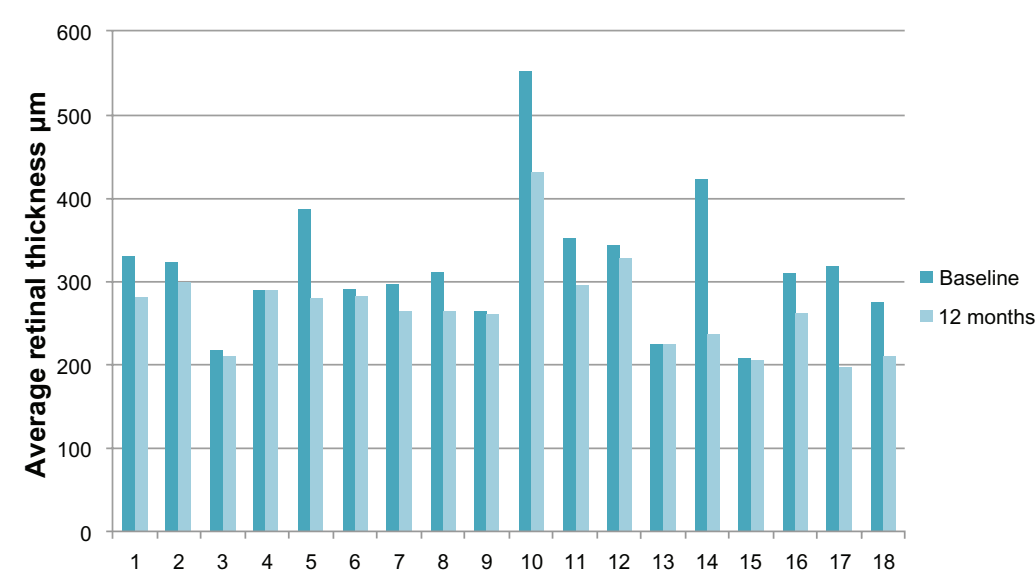

Eye
B

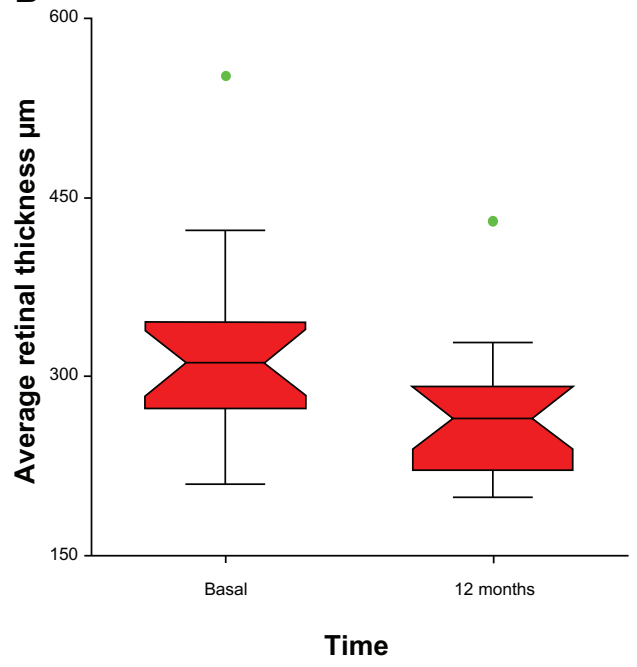

Figure 2 (A) Effect of the curcumin-lecithin formulation (Norflo ${ }^{\circledR}$ ) on OCT retinal thickness after 12 months of treatment. (B) The notched box plot displays the confidence interval around the median which is normally based on the median $\pm 1.57 \times$ interquartile range/square root of $n$. According to the graphical methods for data analysis, if two boxes' notches do not overlap there is 'strong evidence' ( $95 \%$ confidence) that their medians differ. Points outside the whisker boundaries are considered outliers (green = mild).

Abbreviation: OCT, optical coherence tomography.

Note: Norflo $^{\circledR}$, Eye Pharma, Genova, Italy.

and hyperpermeability of the blood-retinal barrier. Such disruption of the retinal pigment epithelium may cause further inflammation leading to decompensation, resulting in a protracted disease course and extensive neurosensory detachment. Although endowed with anti-inflammatory properties, which may be theoretically useful in CSCR, corticosteroids are known to stimulate the mineralocorticoid receptor, leading to vascular hyperpermeability and fluid leakage, ${ }^{33}$ so are involved in the onset and persistence of CSCR and should be avoided in the management of CSCR. Some nonsteroidal anti-inflammatory agents, including ibuprofen and aspirin, have been proposed for the treatment of CSCR, ${ }^{12,34}$ providing a solid rationale for the investigation of natural anti-inflammatory treatments for this condition. Curcumin, the yellow pigment of turmeric, is considered to be a master switch for inflammation, acting at both the functional and genomic levels, and can inhibit proinflammatory transcription factors and enzymes. Curcumin can also reduce expression of vascular endothelial growth factor, and bevacizumab, an antivascular endothelial growth factor A monoclonal antibody, has
1

A

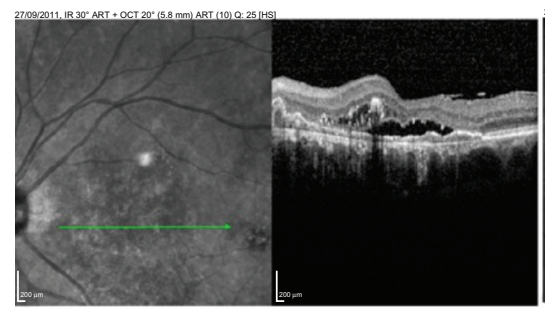

B

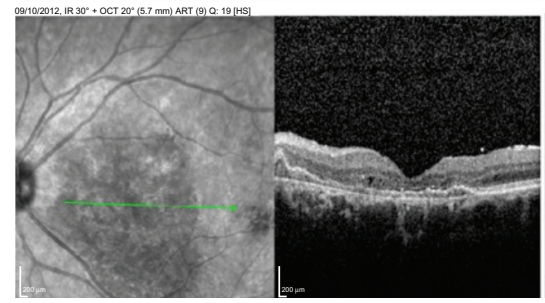

2

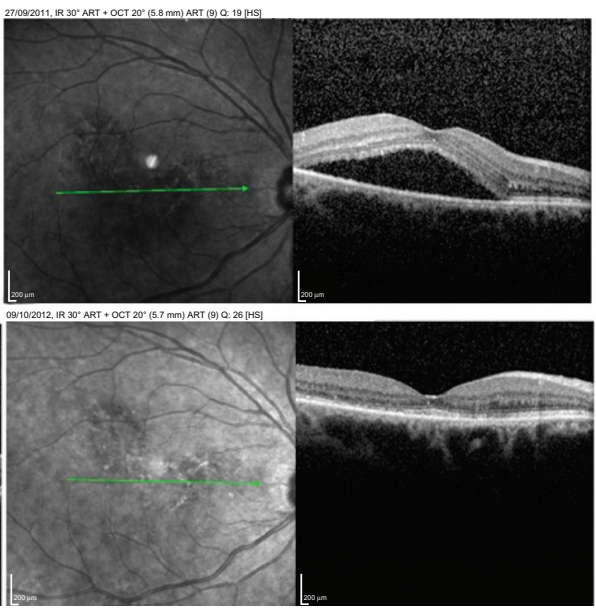

3

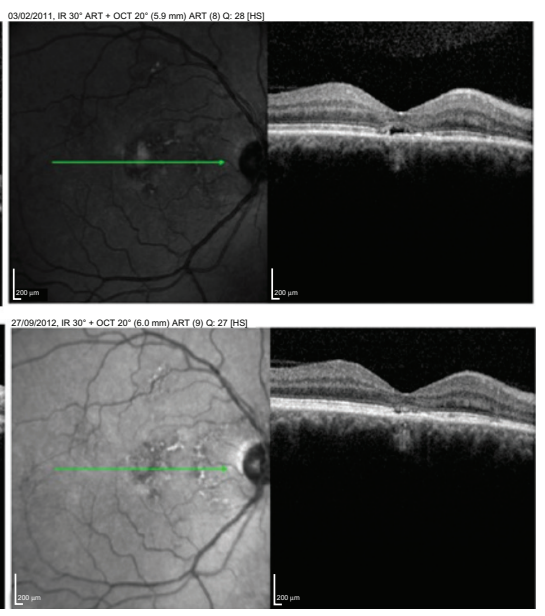

Figure 3 Effect of the curcumin-lecithin formulation (Norflo ${ }^{\circledR}$ ) on OCT retinal thickness after 12 months. The images represent three different cases (from left to right, I-3), evaluated at different times (at first visit, A, and at follow up, B). The green line identifies the area analyzed in cross sectional mode and reported in the image on the right.

Abbreviation: OCT, optical coherence tomography.

Note: Norflo ${ }^{\circledR}$, Eye Pharma, Genova, Italy. 
been suggested for the treatment of CSCR ${ }^{35}$ Curcumin is also an activator of the transcription factor, PPAR $-\gamma,{ }^{36}$ stimulation and upregulation of which is associated with significant anti-inflammatory activity. ${ }^{37}$ The glia and microglia are the main immune cells involved in ocular inflammation, and PPAR- $\gamma$, a sensor of metabolism, is critically involved in the function of these cells. Therefore, modulation of PPAR- $\gamma$ has considerable therapeutic potential in many ocular diseases, including vitreoretinopathy, diabetic retinopathy, glaucoma, and age-related macular degeneration. ${ }^{9}$

Although curcumin is a very promising dietary agent for the treatment of a number of conditions, its introduction into the clinical setting has been hampered by its low bioavailability. The lecithin delivery system for curcuminoids (Meriva) has been developed with the aim of overcoming this problem, and has shown that incorporation of this class of compounds into a phospholipid matrix can achieve therapeutic systemic levels, even in relatively impenetrable tissues. ${ }^{38,39}$ A pharmacokinetic study in humans has confirmed an almost 30-fold increase in absorption of curcumin, thus overcoming the need to administer megadoses of the native compound. ${ }^{38-43}$ Encouraged by evidence of the activity of curcumin in inflammatory eye disease, ${ }^{9,10,17,40,44-52}$ and the improved absorption possible with Meriva, we investigated its potential when formulated as Norflo tablets for the management of CSCR, a chronic relapsing eye disease. Twelve patients were enrolled in this open-label study, corresponding to examination of 18 eyes. All patients completed at least 12 months of follow-up. No dropouts occurred, which was largely attributable to the excellent tolerability of the product. Significant reversal of deteriorating visual acuity and improved histology were observed in all patients. At present, it is difficult to recommend the most appropriate therapeutic plan for CSCR, even in terms of mainstream medication, and this is partially due to the unpredictable nature and evolution of CSCR. However, it is accepted that treatment should be considered in acute cases that do not resolve spontaneously after three months and in chronic cases. ${ }^{2}$ While we cannot exclude the possibility of spontaneous improvement in this study because of our small patient population and the inclusion of various forms of CSCR, the curcumin-lecithin delivery system may still be useful in the treatment of retinal detachment, and could be used as an adjunctive therapy to reduce the number of relapses in more advanced stages of the disease.

\section{Conclusion}

In light of its anti-inflammatory profile and angiogenesismodulating properties, curcumin has great potential in the treatment of inflammatory and neovascular proliferative diseases of the retina sustained by the action of vascular endothelial growth factor. ${ }^{10,17,40,53-55}$ Formulation with lecithin has been shown to be beneficial for the absorption of curcumin, and in this follow-up study we have shown that lecithinized curcumin (Meriva, administered as two Norflo tablets daily) may have beneficial effects in CSCR, reversing deterioration in visual acuity and improving the histological status of the disease. Our study has several obvious limitations in common with other trials in CSCR, ie, the lack of a well defined and widely accepted therapeutic protocol and the unpredictable spontaneous evolution of the condition. Despite these issues, the present study demonstrates a clear reduction in retinal pigment epithelium and neurosensory detachment, in addition to improved visual acuity. Overall, we consider our findings to be promising and worthy of investigation in a future placebo-controlled study involving a larger number of patients.

\section{Acknowledgment}

The authors are grateful to Martino Recchia for statistical analysis of the data collected in this study.

\section{Disclosure}

ST is an employee of Indena SpA which is the manufacturer of Meriva. FM reports no conflicts of interest in this work.

\section{References}

1. Mazzolani F. Pilot study of oral administration of a curcuminphospholipid formulation for treatment of central serous chorioretinopathy. Clin Ophthalmol. 2012;6:801-806.

2. Wang M, Munch IC, Hasler PW, Prunte C, Larsen M. Central serous chorioretinopathy. Acta Ophthalmol. 2008;86:126-145.

3. Graefe AV. Uber centrale recidivierende retinitis [On central recurrent retinitis]. Graefes Arch Clin Exp Ophthalmol. 1866;12:211-215. German.

4. Gass JD. Pathogenesis of disciform detachment of the neuroepithelium. Am J Ophthalmol. 1967;63 Suppl:1-139.

5. Arndt C, Sari A, Ferre M, et al. Electrophysiological effects of corticosteroids on the retinal pigment epithelium. Invest Ophthalmol Vis Sci. 2001;42:472-475.

6. Prunte C, Flammer J. Choroidal capillary and venous congestion in central serous chorioretinopathy. Am J Ophthalmol. 1996;121:26-34.

7. Ochiai J, Kato M, Tanikawa H, Kobayashi Y. [The changes over time in areas of abnormal choroidal staining in central serous chorioretinopathy.] Nippon Ganka Gakkai zasshi. 2002;106:583-589. Japanese.

8. Chong CF, Yang D, Pham TQ, Liu H. A novel treatment of central serous chorioretinopathy with topical anti-inflammatory therapy. $B M J$ Case Rep. 2012;2012. pii: bcr2012006970.

9. Malchiodi-Albedi F, Matteucci A, Bernardo A, Minghetti L. PPARgamma, microglial cells, and ocular inflammation: new venues for potential therapeutic approaches. PPAR Res. 2008;2008:295784.

10. Murata T, He S, Hangai M, et al. Peroxisome proliferator-activated receptor-gamma ligands inhibit choroidal neovascularization. Invest Ophthalmol Vis Sci. 2000;41:2309-2317. 
11. Iijima $\mathrm{H}$, Iida $\mathrm{T}$, Murayama $\mathrm{K}$, Imai $\mathrm{M}$, Gohdo T. Plasminogen activator inhibitor 1 in central serous chorioretinopathy. Am J Ophthalmol. 1999; 127:477-478.

12. Caccavale A, Imparato M, Romanazzi F, Negri A, Porta A, Ferentini F. A new strategy of treatment with low-dosage acetyl salicylic acid in patients affected by central serous chorioretinopathy. Med Hypotheses. 2009;73:435-437.

13. Gupta SC, Kismali G, Aggarwal BB. Curcumin, a component of turmeric: from farm to pharmacy. BioFactors. 2013;39:2-13.

14. Shehzad A, Rehman G, Lee YS. Curcumin in inflammatory diseases. Bio Factors. 2013;39:69-77.

15. Esatbeyoglu T, Huebbe P, Ernst IM, Chin D, Wagner AE, Rimbach G. Curcumin - from molecule to biological function. Angew Chem Int Ed Engl. 2012;51:5308-5332.

16. Zhou H, Beevers CS, Huang S. The targets of curcumin. Curr Drug Targets. 2011;12:332-347.

17. Bonne C. [PPAR gamma: a novel pharmacological target against retinal and choroidal neovascularization.] J Fr Ophtalmol. 2005;28:326-330. French.

18. Siddiqui AM, Cui X, Wu R, et al. The anti-inflammatory effect of curcumin in an experimental model of sepsis is mediated by up-regulation of peroxisome prolif erator-activated receptor-gamma. Crit Care Med. 2006;34:1874-1882.

19. Jiang C, Ting AT, Seed B. PPAR-gamma agonists inhibit production of monocyte inflammatory cytokines. Nature. 1998;391:82-86.

20. Manikandan R, Thiagarajan R, Beulaja S, Sudhandiran G, Arumugam M. Effect of curcumin on selenite-induced cataractogenesis in Wistar rat pups. Curr Eye Res. 2010;35:122-129.

21. Manikandan R, Thiagarajan R, Beulaja S, Sudhandiran G, Arumugam M. Curcumin prevents free radical-mediated cataractogenesis through modulations in lens calcium. Free Radic Biol Med. 2010;48:483-492.

22. Manikandan R, Thiagarajan R, Beulaja S, et al. Anti-cataractogenic effect of curcumin and aminoguanidine against selenium-induced oxidative stress in the eye lens of Wistar rat pups: An in vitro study using isolated lens. Chem Biol Interact. 2009;181:202-209.

23. Allegri P, Mastromarino A, Neri P. Management of chronic anterior uveitis relapses: efficacy of oral phospholipidic curcumin treatment. Long-term follow-up. Clin Ophthalmol. 2010;4:1201-1206.

24. Wang LL, Sun Y, Huang K, Zheng L. Curcumin, a potential therapeutic candidate for retinal diseases. Mol Nutr Food Res. February 18, 2013. [Epub ahead of print.]

25. Cuomo J, Appendino G, Dern AS, et al. Comparative absorption of a standardized curcuminoid mixture and its lecithin formulation. $J$ Nat Prod. 2011;74:664-669.

26. Ledda A, Belcaro G, Dugall M, et al. Meriva(R), a lecithinized curcumin delivery system, in the control of benign prostatic hyperplasia: a pilot, product evaluation registry study. Panminerva Med. 2012; 54(1 Suppl 4):17-22.

27. Steigerwalt R, Nebbioso M, Appendino G, et al. Meriva(R), a lecithinized curcumin delivery system, in diabetic microangiopathy and retinopathy. Panminerva Med. 2012;54(1 Suppl 4):11-16.

28. Appendino G, Belcaro G, Cornelli U, et al. Potential role of curcumin phytosome (Meriva) in controlling the evolution of diabetic microangiopathy. A pilot study. Panminerva Med. 2011;53(3 Suppl 1):43-49.

29. Belcaro G, Cesarone MR, Dugall M, et al. Efficacy and safety of Meriva(R), a curcumin-phosphatidylcholine complex, during extended administration in osteoarthritis patients. Altern Med Rev. 2010;15:337-344.

30. Belcaro G, Cesarone MR, Dugall M, et al. Product-evaluation registry of Meriva(R), a curcumin-phosphatidylcholine complex, for the complementary management of osteoarthritis. Panminerva Med. 2010;52(2 Suppl 1):55-62.

31. Ibrahim A, El-Meligy A, Fetaih H, Dessouki A, Stoica G, Barhoumi R. Effect of curcumin and Meriva on the lung metastasis of murine mammary gland adenocarcinoma. In Vivo. 2010;24:401-408.

32. Bouzas EA, Moret P, Pournaras CJ. Central serous chorioretinopathy complicating solar retinopathy treated with glucocorticoids. Graefes Arch Clin Exp Ophthalmol. 1999;237:166-168.
33. Zhao M, Celerier I, Bousquet E, et al. Mineralocorticoid receptor is involved in rat and human ocular chorioretinopathy. $J$ Clin Invest. 2012;122:2672-2679.

34. Caccavale A, Romanazzi F, Imparato M, Negri A, Morano A, Ferentini F. Central serous chorioretinopathy: a pathogenetic model. Clin Ophthalmol. 2011;5:239-243.

35. Schaal KB, Hoeh AE, Scheuerle A, Schuett F, Dithmar S. Intravitreal bevacizumab for treatment of chronic central serous chorioretinopathy. Eur J Ophthalmol. 2009;19:613-617.

36. Chen L, Yang P, Kijlstra A. Distribution, markers, and functions of retinal microglia. Ocul Immunol Inflamm. 2002;10:27-39.

37. Jacob A, Wu R, Zhou M, Wang P. Mechanism of the anti-inflammatory effect of curcumin: PPAR-gamma activation. PPAR Res. 2007;2007: 89369.

38. Marczylo TH, Steward WP, Gescher AJ. Rapid analysis of curcumin and curcumin metabolites in rat biomatrices using a novel ultraperformance liquid chromatography (UPLC) method. J Agric Food Chem. 2009;57: 797-803.

39. Marczylo TH, Verschoyle RD, Cooke DN, Morazzoni P, Steward WP, Gescher AJ. Comparison of systemic availability of curcumin with that of curcumin formulated with phosphatidylcholine. Cancer Chemother Pharmacol. 2007;60:171-177.

40. Wang YJ, Pan MH, Cheng AL, et al. Stability of curcumin in buffer solutions and characterization of its degradation products. J Pharm Biomed Anal. 1997;15:1867-1876.

41. Anand P, Kunnumakkara AB, Newman RA, Aggarwal BB. Bioavailability of curcumin: problems and promises. Mol Pharm. 2007;4:807-818.

42. Li L, Braiteh FS, Kurzrock R. Liposome-encapsulated curcumin: in vitro and in vivo effects on proliferation, apoptosis, signaling, and angiogenesis. Cancer. 2005;104:1322-1331.

43. Jurenka JS. Anti-inflammatory properties of curcumin, a major constituent of Curcuma longa: a review of preclinical and clinical research. Altern Med Rev. 2009;14:141-153.

44. Lal B, Kapoor AK, Asthana OP, et al. Efficacy of curcumin in the management of chronic anterior uveitis. Phytother Res. 1999;13:318-322.

45. Lal B, Kapoor AK, Agrawal PK, Asthana OP, Srimal RC. Role of curcumin in idiopathic inflammatory orbital pseudotumours. Phytother Res. 2000;14:443-447.

46. Sharma RA, Steward WP, Gescher AJ. Pharmacokinetics and pharmacodynamics of curcumin. Adv Exp Med Biol. 2007;595:453-470.

47. Lao CD, Ruffin MTt, Normolle D, et al. Dose escalation of a curcuminoid formulation. BMC Complement Altern Med. 2006;6:10.

48. Bisht S, Feldmann G, Soni S, Ravi R, Karikar C, Maitra A. Polymeric nanoparticle-encapsulated curcumin ("nanocurcumin"): a novel strategy for human cancer therapy. J Nanobiotechnology. 2007;5:3.

49. Maiti K, Mukherjee K, Gantait A, Saha BP, Mukherjee PK. Curcuminphospholipid complex: preparation, therapeutic evaluation and pharmacokinetic study in rats. Int J Pharm. 2007;330:155-163.

50. Aggarwal BB, Sung B. Pharmacological basis for the role of curcumin in chronic diseases: an age-old spice with modern targets. Trends Pharmacol Sci. 2009;30:85-94.

51. Barry J, Fritz M, Brender JR, Smith PE, Lee DK, Ramamoorthy A. Determining the effects of lipophilic drugs on membrane structure by solid-state NMR spectroscopy: the case of the antioxidant curcumin. J Am Chem Soc. 2009;131:4490-4498.

52. Aggarwal BB, Harikumar KB. Potential therapeutic effects of curcumin, the anti-inflammatory agent, against neurodegenerative, cardiovascular, pulmonary, metabolic, autoimmune and neoplastic diseases. Int $J$ Biochem Cell Biol. 2009;41:40-59.

53. Jeong SJ, Koh W, Lee EO, et al. Antiangiogenic phytochemicals and medicinal herbs. Phytother Res. 2011;25:1-10.

54. Arbiser JL, Klauber N, Rohan R, et al. Curcumin is an in vivo inhibitor of angiogenesis. Mol Med. 1998;4:376-383.

55. Kowluru RA, Kanwar M. Effects of curcumin on retinal oxidative stress and inflammation in diabetes. Nutr Metab (Lond). 2007;4:8. 
Clinical Ophthalmology

\section{Publish your work in this journal}

Clinical Ophthalmology is an international, peer-reviewed journal covering all subspecialties within ophthalmology. Key topics include: Optometry; Visual science; Pharmacology and drug therapy in eye diseases; Basic Sciences; Primary and Secondary eye care; Patien Safety and Quality of Care Improvements. This journal is indexed on

PubMed Central and CAS, and is the official journal of The Society of Clinical Ophthalmology (SCO). The manuscript management system is completely online and includes a very quick and fair peer-review system, which is all easy to use. Visit http://www.dovepress.com/ testimonials.php to read real quotes from published authors. 